\title{
Recent Research on Occupational Animal Exposures and Health Risks: A Narrative Review
}

\author{
Caroline Dignard $^{1}$ - Jessica H. Leibler ${ }^{2}$ \\ Published online: 10 December 2019 \\ (C) Springer Nature Switzerland AG 2019
}

\begin{abstract}
Purpose of Review In the last year, an increasing number of studies have reported on methicillin-resistant Staphylococcus aureus (MRSA) transmission in Africa and Asia and in migrant workers. We reviewed original research on occupational health and safety of animal workers published from January 1, 2018, through June 30, 2019, with a targeted focus on infectious disease studies published in these populations.

Recent Findings Studies focused on occupational exposures to infectious agents, dust and allergens, pesticides, and occupational injury. Research on zoonotic MRSA used whole genome-sequencing technologies to evaluate transmission in Africa and Asia. Swine worker exposure to porcine coronavirus and emerging influenza A viruses was documented in China. 16s RNA amplicon sequencing identified distinct microbiota compositions in households with active animal farmers. Multiple bioaerosol exposures were assessed for industrial dairy workers. Occupational injury studies highlighted the struggles of Latino animal workers in the USA.

Summary These studies highlighted the global expansion of zoonotic antibiotic resistance and identified novel occupational zoonoses of concern. The integration of microbiome assessment and compound mixtures into the evaluation of dust and endotoxin exposures for animal workers marks a new direction for this work.
\end{abstract}

Keywords Food animal worker - Occupational health · Methicillin-resistant, Staphylococcus aureus · Zoonotic influenza . Occupational injury $\cdot$ Endotoxin

\section{Introduction}

Occupational exposure to animals is associated with a myriad of health and safety risks, including zoonotic infections, occupational injury, respiratory disease, and cancer [1-4]. In the USA, food animal workers have elevated workplace mortality and injury rates compared with workers in other industries, highlighting the occupational risks involved in the profession [5]. In the last 15 years, research on zoonotic infection risk has dominated the occupational health literature on the animal

This article is part of the Topical Collection on Occupational Health (M Friesen, K Applebaum Section Editors)

Jessica H. Leibler

jleibler@bu.edu

1 Williams College, Williamstown, MA 01267, USA

2 Department of Environmental Health, Boston University School of Public Health, 715 Albany St, Boston, MA 02118, USA workforce, highlighting in particular exposure risk to drugresistant bacteria and influenza viruses and subsequent transmission from workers to the general public [6-8].

In the last 50 years, industrialization and corporate consolidation have characterized the food animal production industry, first in the USA and Europe and then globally $[9,10]$. These trends have fundamentally altered occupational exposures for the food animal workforce, by increasing and intensifying specific occupational exposures that impart health risks [11]. For workers, the intensity of animal exposures has increased, as industrial farms can hold tens of thousands of animals on site. The dramatic increase in the number of animals housed together in confinement contributes to intensified worker exposure to animals and animal products, including allergens and fecal materials $[12,13]$.

Notably, the introduction of antibiotics into animal production - in an effort to facilitate the higher carrying capacity of industrial farms - has resulted in worker exposures to antibiotic-resistant bacterial infections [14]. Since 2005, research on zoonotic methicillin-resistant Staphylococcus 
aureus (MRSA), particularly the livestock-associated MRSA strains ST398 and CC9, have identified important public health concerns stemming from the misuse and overuse of these antibiotics in agriculture [15-17]. Likewise, the H5N1 epidemic in poultry in Asia in the mid-1990s and the 2009 H1N1 swine flu human pandemic, highlight the role of industrial systems in the ecology of pandemic influenza [18-20]. The emergence and re-emergence of zoonotic pathogens with potential to infect humans remains a critical public health issue, and animal workers are at the front lines [21-23].

The demographics of this workforce have also changed significantly in recent decades, with Latino and immigrant workforce currently dominating the worker population in the USA. This change has resulted in additional challenges for the workforce, including language barriers, immigration status concerns, stagnant and falling wages, and other socioeconomic and political stressors [24]. The relationship between these stressors and occupational injury and mental health has been documented in recent years [25-28].

Many animal workers experience occupationally induced respiratory disease, including allergies, asthma, and rhinitis $[29,30]$. High levels of inhalable dust and endotoxins are considered the primary exposures of concern in regard to respiratory disease; however evaluating these often complex mixtures-including animal products, dust, pathogens, and chemicals - is typically limited to single-compound analyses. As a result, much remains unknown about the etiology of occupational respiratory disease among animal workers.

Across agricultural industries, the use of pesticides is associated with a variety of health risks, including reproductive, dermatological, and neurological problems as well as cancer [31-34]. Pesticide use is common among animal facilities, particularly those that engage in both crop and livestock production, yet pesticide exposures have received limited scrutiny to date in research on animal workers. On both industrial and small-scale animal farms, chemical disinfectants are used to prevent transmission of infectious agents and may result in health concerns for workers $[35,36]$. While the biosecurity literature has promoted the use of disinfectants to prevent disease transmission, health risks associated with worker exposure to these compounds are largely unstudied.

In this manuscript, we review occupational health studies published in the last 18 months in the peer-reviewed literature focused on the health and safety of animal workers. Our intention was to highlight important findings and new directions for this research area.

\section{Methods}

We searched PubMed, Web of Science, and Google Scholar for terms and keywords relating to occupational health and animal exposure, including combinations of the following worker and health-specific terms: "food animal worker", "animal worker", "industrial animal worker", "animal farmer", "occupational injury", "occupational health", "health and safety", and "occupational safety". A date range of January 1,2018 , through June 30, 2019, was included so as to maximize identification and in-depth discussion of recent research. A total of 726 distinct manuscripts were identified upon initial search. Following review by two researchers (C.D., J.H.L.), these papers were reduced to 37 manuscripts of relevance to the current topic. These papers included three review manuscripts and 34 original research studies. We included the reviews in our analysis because they provide important insight and expert consensus as to the direction of important fields (biosecurity for live bird market workers; respiratory exposures and disease among food animal workers; and effectiveness of health and safety trainings and interventions for Latino animal workers). The 37 manuscripts were organized in an Excel spreadsheet and read by two researchers. A narrative synthesis approach was used to extract central themes, findings, and conclusions. Based on our a priori knowledge of the field and an assessment of other recent manuscripts in the literature, we identified manuscripts we believed to be of elevated significance to readers engaged in animal worker health and safety work and research, and we discuss those studies in greater detail.

\section{Results}

The manuscripts published during this 18-month period were predominantly in the following topic areas: infectious disease and pathogen exposures; respiratory disease and irritants; pesticide and chemical exposures, including neurological toxicants and carcinogens; and occupational injury. Below, we summarize the key findings from manuscripts published in each of these topic areas, highlighting the papers that in our opinion are of greatest importance for the field.

\section{Infectious Disease}

The majority of manuscripts identified in our review (18/37; $49 \%$ ) were focused on animal worker exposure to infectious agents, zoonotic pathogen carriage or infection within this workforce, or pathogen contamination of the work environment. The infectious disease papers are summarized in Table 1.

\section{MRSA}

The reviewed manuscripts documented the identification of livestock-associated MRSA in animals and humans in regions around the world and in animal-exposed professions in which MRSA had not previously been assessed. A study in 


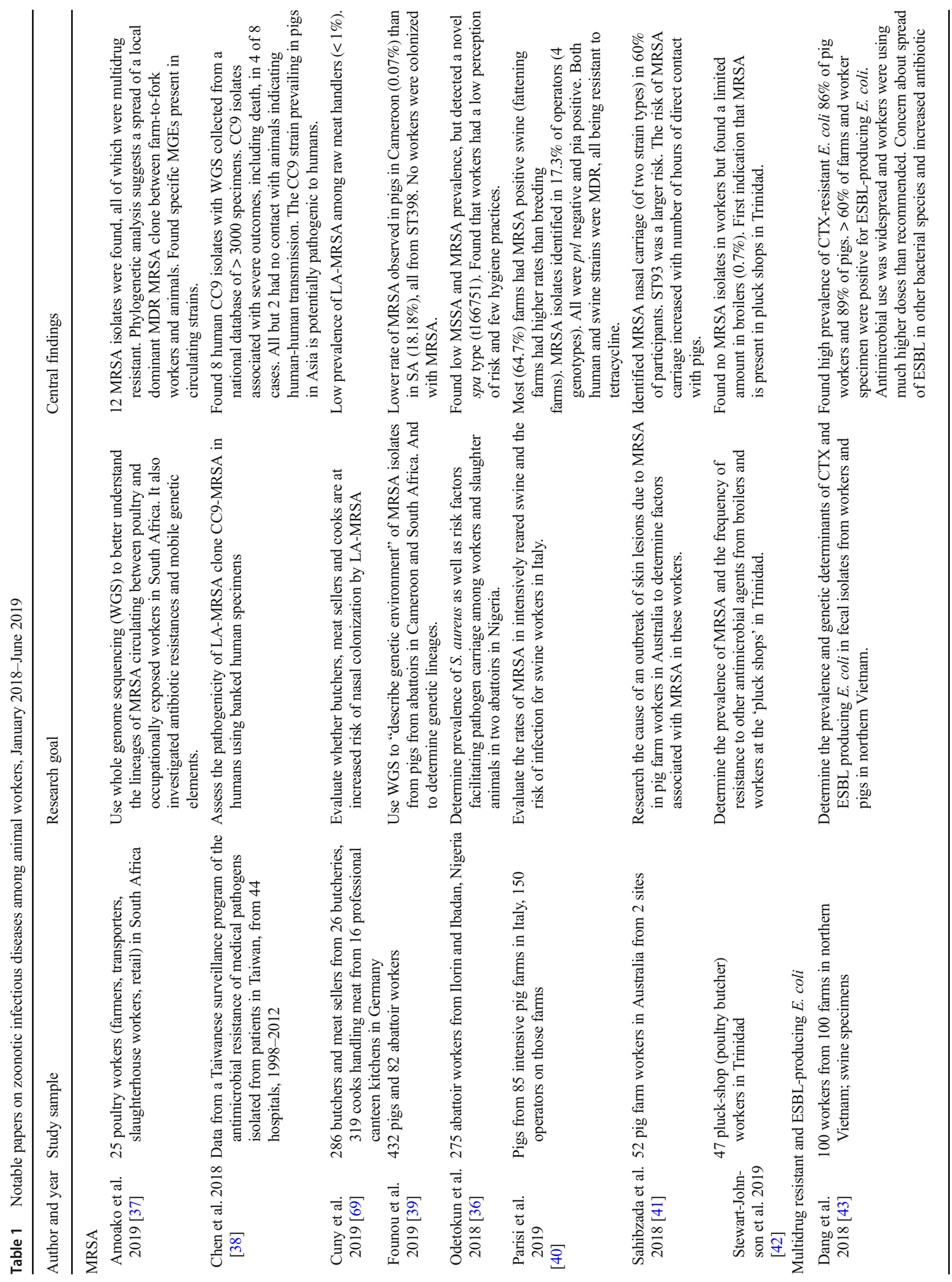




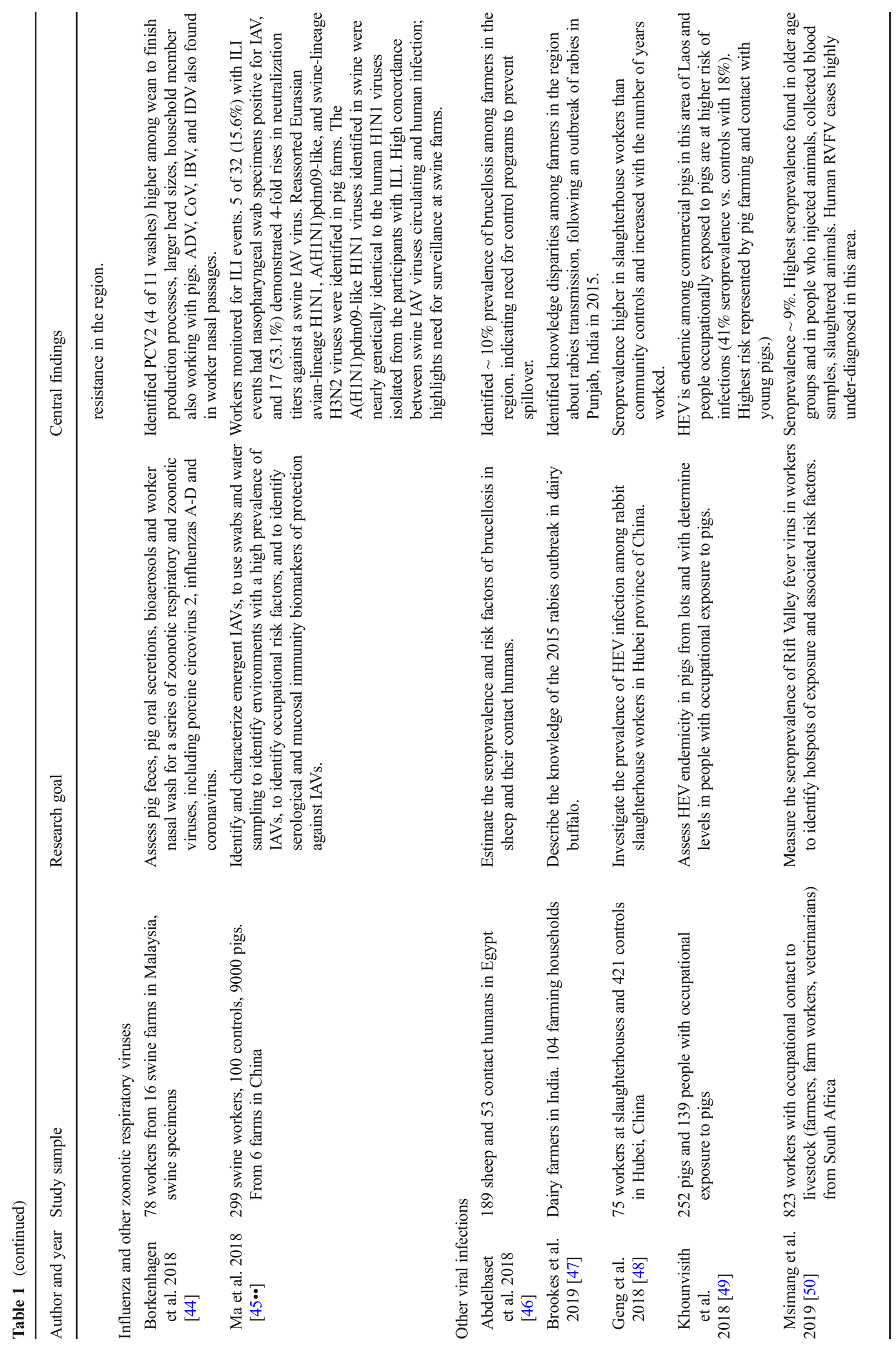


Nigeria identified low prevalence of LA-MRSA among abattoir workers $(1.1 \%)$ and distinguished a diversity of $S$. aureus spa types in the work environment, including a novel spa type (t16751) [36]. The first published study of LA-MRSA among workers and livestock in Trinidad identified a low prevalence among animals $(<1 \%)$ and no worker carriage, indicating limited transmission in this country [42]. A case study of MRSA among swine and workers on an Australian swine farm where workers were affected by skin lesions identified high odds of MRSA nasal carriage among the workers (OR 23.6) and a dose-response relationship of MRSA nasal carriage in association with duration of time spent working with pigs [41]. A study in Italy reinforced the elevated prevalence of ST398 among industrial swine (approx. 65\%) and swine workers $(17 \%)$ in that country and highlighted a component of the production cycle (fattening) in which workers had higher risk of exposure [40]. Cuny and colleagues assessed MRSA nasal colonization among butchers and food preparers in Germany to evaluate whether these persons with contact with raw meat were colonized with livestock-associated MRSA, and found limited evidence of colonization $(<1 \%)$ [51]. These studies continue to expand our knowledge of the distribution of livestock-associated MRSA, both by industry and by geographic region.

Whole genome-sequencing (WGS) technology was used to elucidate transmission pathways in two studies conducted in Africa. Amoako and colleagues took a comprehensive approach and used WGS to evaluate MRSA along the "farm to fork" continuum in the intensive poultry industry in South Africa [37]. The authors evaluated samples collected from the farms, transport vehicles, slaughterhouses, and retail outlets, as well as fecal and nasal specimen from workers along the production process. The authors document the widespread distribution of MRSA clone ST612-CC8_t1257-SCCmec_type_IVd (2B) throughout the production cycle. They hypothesize that the multidrug resistance of this clone is mediated by mobile genetic elements, due to the similarity of resistance patterns between the human and animal specimen. The identified prevalent clone is considered both nosocomial and community-associated, highlighting the public health risks associated with the poultry industry in South Africa. This work and the study in Cameroon, detailed below, are of relevance due to the rapid intensification and expansion of industrial food animal production into Africa and the limited research to date on the public health consequences of this industrial growth.

A second study in Africa used WGS to identify the genetic lineage of MRSA isolates from swine slaughterhouses in South Africa and Cameroon [39]. These authors found approximately $18 \%$ prevalence in pigs in South Africa but a low prevalence in Cameroon $(<1 \%)$, with no workers colonized in either country. All isolates were ST398, a distinction from the Amoako study. These findings highlight potential differences in MRSA carriage by species and/or region and also suggest that production or environmental containment practices may differ among countries and corporations in relevant ways for public health.

Chen et al. used WGS to identify whether $\mathrm{CC}$, the predominant livestock-associated MRSA strain in Asia, was associated with pathogenicity in humans [38]. The authors screened MRSA isolates from a national database in Taiwan and found CC9 had a low prevalence $(0.24 \%)$; however, these isolates were associated with invasive disease, including bacteremia leading to death and osteomyelitis in four of the eight identified cases. The remaining four cases were associated with mild disease or colonization without disease. Of note, only two of the eight cases had documented exposure to pigs, considered the main CC9 reservoir in the region. This important paper highlights two core concepts: (1) while rare in humans, CC9 may be associated with significant pathogenicity in humans, including death and (2) nosocomial or community transmission for this pathogen should be considered. Like the African studies, this paper elucidates the public health risks from animal work and highlights the potential role of animal workers at the front lines of exposure to zoonotic pathogens of broader health concern.

\section{Other Antibiotic-Resistant Bacterial Infections}

Dang et al. reported on a study of cefotaxime (CTX)-resistant and extended-spectrum $\beta$-lactamase (ESBL) producing Escherichia coli (E. coli) recovered from swine workers and pigs in northern Vietnam, a region characterized by rapid growth in industrial swine production and heavy agricultural antibiotic usage [43]. ESBLs are of particular concern because these genes are encoded by plasmids that are easily transferred across bacterial species, potentially resulting in widespread antibiotic resistance. The authors observed high prevalence of CTX-resistant E. coli among both workers and pigs (86\% of pig workers and $89 \%$ of pigs) on 100 farms studied. ESBLproducing $E$. coli was detected from more than $65 \%$ of both pigs and farms. This paper highlights significant concern regarding potential spillover of drug-resistant bacteria from swine to humans in this region, as well as the likelihood of dissemination of the ESBL MGEs.

\section{Influenza Viruses}

Research during this period focused on zoonotic influenza of multiple subtypes, including the emerging influenza $\mathrm{D}$ virus. Ma et al. published findings from a longitudinal study of swine workers, swine, and environmental sampling in China $[45 \bullet \cdot]$. Notably, in this study, workers were monitored for influenza-like illness along with surveillance sampling, so as to identify active symptoms associated with infection. Approximately $15 \%$ of workers with ILI were positive for influenza A virus, with more than $50 \%$ of those infected with 
a putative swine lineage virus. Additionally, high concordance was noted between $\mathrm{A}(\mathrm{H} 1 \mathrm{~N} 1)$ pdm09-like H1N1 viruses isolated from workers with ILI and IAV circulating among swine, indicating species crossover. A second study, led by Borkenhagen et al. identified influenza B and influenza D viruses in swine worker nasal passages during a surveillance study in Malaysia [44]. The authors also recovered porcine circovirus 2 in worker nasal specimen as well as in pig specimen, indicating zoonotic concern associated with this viral pathogen of growing concern in Asia. We would also direct readers interested in zoonotic influenza emergence to two valuable review papers published in the last year this topic, by Zhou et al. and Bailey et al $[52,53]$.

\section{Other Viral Infections}

Animal worker exposure to hepatitis E virus (HEV) was explored in two notable papers, both of which extended the prior paradigm of HEV research to include new populations or production specifics. A study in Hubei, China, identified elevated seroprevalence among rabbit slaughterhouse workers compared with community controls and observed a doseresponse relationship between increasing seroprevalence associated with duration of employment [48]. Khounvisith and colleagues evaluated HEV seroprevalence among commercial pig workers in Laos, a region with HEV endemicity among swine [49]. The authors observed $41 \%$ of workers were HEV seroprevalent, compared with $18 \%$ of controls, and workers exposed to piglets during the growth process were at elevated risk.

Other authors highlighted additional emerging zoonotic viral pathogens in the food animal workforce, including a report of brucellosis among sheep farmers in Egypt and knowledge and biosecurity practices among Indian animal farmers about rabies [46, 47]. Msimang and colleagues reported on Rift Valley fever seroprevalence among animal farmers and veterinarians in South Africa, concluding that infection with this re-emerging pathogen is likely notably higher than previously recognized and under-diagnosed in the region [50].

\section{Respiratory Disease}

We identified eight original research papers and one review study focused on topics related to respiratory disease, exposure to allergens and dust, and airborne bacteria among animal workers. These papers expanded the literature in two core ways: (1) a focus on combined and interacting respiratory exposures, rather than single-exposure assessments and (2) the use of 16s RNA amplicon sequencing technology to evaluate house microbiota in farmer's homes and correlating these data to endotoxin levels. Key papers are discussed below.

Davidson et al. conducted personal exposure monitoring of bioaerosol exposures, including inhalable dust, endotoxin, 3-hydroxy fatty acids, muramic acid, ergosterol, and ammonia among workers at large dairies in the Western USA [54•]. This paper marks one of the early studies to consider multiple, and interacting, respiratory exposures in this population. The authors conclude that a majority of these workers were exposed to endotoxin concentrations that exceed recommended guidelines $(89 \%)$. Workers were also exposed to inhalable dust and ammonia at levels above guidelines. The authors also evaluated the correlation between pairs of these exposures by different dairy tasks, another novelty of this work. Lee et al. used 16s RNA amplicon sequencing to evaluate bacterial composition of dust samples recovered from households of active and former farmers recruited in the Agricultural Lung Health Study, a nested study of the Agricultural Health Study in North Carolina and Iowa [55••]. Current farming was a significant predictor of the composition and diversity of house dust microbiota. Animal farming was uniquely associated with Firmicutes and Proteobacteria phyla, with Bacillaceae, Bacteroidaceae, Xanthomonadaceae, Streptococcaceae, and Lactobacillacae also identified in dust specimen from homes with animal farmers. The authors identified taxa associated with endotoxin concentration. Asthma status was not associated with bacterial diversity or composition. This paper is notable for its integration of traditional exposure assessment approaches to endotoxin and 16s RNA amplicon sequencing technology for evaluating microbiota, and for contributing detail to our understanding of household-level exposures experienced by animal workers and their families.

Other notable manuscripts this year included: a study of bacterial and fungal exposures among Portuguese veterinarians, exposures to ammonia, VOCs, and fungus among swine workers during the summer and winter seasons in Poland, and a study from Australia of worker exposure to asthmagens derived from animals or fish/shellfish (El Zaemey et al.) [56-58]. The latter study was notable for its large sample ( $n$ $=4000)$ and its comparison of farmers and animal workers to community controls in a national agricultural study. Additionally, an excellent consensus paper published by the European Academy of Allergy and Clinical Immunology highlights the state of the literature on respiratory disease and animal workers, specifically food processing workers, in Europe, focusing on all elements of the food production chain [59].

\section{Pesticides and Chemical Exposure}

Studies of pesticide and chemical exposures among animal workers highlighted pesticides usage in livestock production may increase the risk of Parkinson's disease (PD) among farmers. While this relationship has been previously assessed in crop farmers, the identification of animal farmers as a population at risk due to shared exposures is a notable contribution of work from this year. Pouchieu and colleagues evaluated the 
risk of PD among both livestock and crop farmers in France exposed to pesticides in the AGRICAN cohort [60]. The crop matrix PESTIMAT was used to evaluate exposure to active ingredients and duration of lifelong use, and the implementation of this matrix again reinforces the interest in evaluating complex and realistic mixture scenarios for worker exposures. In this study, cattle workers in particular had an elevated risk of PD, with dithiocarbamate fungicides, rotenone and the herbicides diquat and paraquat identified as compounds of concern for this occupational group.

Additionally, further studies elucidate carcinogenic compounds beyond pesticides that animal workers may be exposed to, highlighting cancer research as an underexplored area for consideration in this population. Darcey and colleagues conducted a cross-sectional study to evaluate exposure to solar radiation, diesel engine exhaust, and solvents among Australian farmers [61]. Exposure to these carcinogens was highest for farmers with mixed livestock and crop production, again highlighting unique risk profiles for workers who engage in multiple agricultural activities.

Hoffman et al. evaluated serum immune markers in a subset of AHS participants who were swine farmers to consider an immunological explanation for the inverse relationship between swine farming and lung cancer, which is hypothesized due to endotoxin exposure [62]. The authors observed that macrophage-derived chemokine (CCL22), which is believed to contribute to lung carcinogenesis, was lower in swine farmers compared to cattle farmers with a $26 \%$ reduction in levels among farmers at the largest farms (> 6000 head), suggesting a dose-response relationship. These manuscripts highlight the complex health effects associated with occupational animal exposure and indicate how emerging technologies and personal monitoring can inform the biological basis of epidemiologic observations.

\section{Occupational Injury}

Reviewed manuscripts largely focused on the experiences of Latino immigrant and migrant farmworker populations in the USA, who comprise a majority of the US food animal workforce. We note a limited number of peer-reviewed original research publications on occupational injury during the short period of our review. We identified four published epidemiological studies of occupational injury in the animal workforce as well as three studies evaluating effectiveness of injury prevention training. A small study conducted in Missouri examined self-reported injury and health status among Latino immigrant workers. Their results indicated a high prevalence of workers rating their health as fair or poor, along with high prevalence of occupational injury [63]. Clouser and colleagues found that occupational injury was more likely for Latino farmworkers in the USA if they self-reported work stress, supervisor unfairness, or supervisor inability to speak
Spanish [64]. These findings reinforce that immigrant Latino and migrant workers in the animal industry need additional resources and supports to successfully mitigate injury risk.

Bush and colleagues evaluated the causes of missed work among a sample of Latino horse workers in the USA in an attempt to evaluate the causes of occupational illnesses [65]. The authors found that having at least one child, poor selfrated health, and elevated stress were associated with missed work, highlighting the intersecting role of personal and workrelated factors for these workers. An assessment of OSHA's dairy-focused local emphasis programs (LEPs) in Wisconsin and New York by Liebman et al. found that the OSHA's recent initiative to reduce injury and hazard in the dairy industry improved farmers' ability to recognize occupational hazards [66]. The authors found that the LEPs motivated participating dairy producers in these two states to address hazards, such as correct signage, repairs and fit for PPE, and manure management and also encouraged workers to advocate for health care needs.

Rodriguez et al. evaluated the effectiveness of delivering health and safety training using mobile platforms to US dairy workers with limited English proficiency [67]. This method was successful, with workers enrolled $(n=1436)$ demonstrating a $18 \%$ mean increase from pre- to post-test knowledge of workplace safety practices $(p<0.05)$. This paper is of particular note given the proliferation of smartphones and the increasing proportion of the food animal workforce with limited English proficiency. Rodriguez and colleagues noted that more than $1 / 5$ of the participants in their study spoke a Central American indigenous language and were able to receive training through smartphone applications and translation, highlighting the power of this technology to reach many workers with necessary education.

Caffaro and colleagues conducted a literature review on occupational safety and health training programs addressing migrant farmworkers, including animal workers, to determine the effectiveness of the standard programs in place [68]. The majority of the reviewed studies found the training programs to be ineffective, with no or little difference in injury outcomes with or without the standard training programs. The authors recommended an increase in participatory approaches and multilingual offerings so as to improve the effectiveness of these programs for migrant workers. Continued efforts to evaluate the effective means of developing and delivering injury prevention and health promotion training to the changing and diverse food animal workforce is an important theme of study.

\section{Conclusions}

Research in 2018 and early 2019 on occupational health and safety topics involving animal workers highlighted the risks and interventions associated with infectious disease, 
respiratory disease, chemical exposure, and occupational injury. In the realm of infectious disease, these studies identified an expanding, and concerning, geographical distribution of MRSA as well as novel transmission pathways. The expansion of MRSA into Africa is of particular note, as the continent has witnessed rapid intensification of food animal production and demand for industrial meat products in recent years. Given the known consequences of unregulated antibiotic usage in animal production for public health and the emergence of LA-MRSA, surveillance, and regulation of LA-MRSA in this region is a critically important direction for future research. In the absence of antibiotic stewardship, interventions to protect workers from zoonotic antibiotic resistant infections - building on the experiences in Europe and the USA - would improve African worker health.

Likewise, the discovery of MRSA strain CC9 among human patients in Taiwan, and the association of this strain with severe illness and death, signifies an important direction for future research. While highly prevalent in livestock populations in Asia, CC9 has not been considered a human pathogen of significance. Chen et al.'s paper should reignite interest in this strain as an important, if rare, contributor to severe illness in humans, with surveillance targeting food animal workers at the front lines of exposure.

Research on zoonotic influenza viruses identified species spillover from swine farming into the food animal workforce, highlighting the importance of this pathway, and this industry for surveillance and pandemic influenza prevention. Bailey and colleagues nicely highlight the recent expansion of zoonotic influenza research, notably the discovery of zoonotic influenza D virus, in their review on this topic [48]. Continued research on influenza transmission at the humananimal interface in food animal production remains a critically important area for continued work.

Likewise, research on behaviors and practices that affect worker exposure, as well as intervention evaluation studies, are central. Studies of respiratory irritants and disease integrated new technologies into multi-exposure assessments, including 16s RNA amplicon sequencing technology. The incorporation of metagenomics approaches will likely mark exposure assessment studies in the future, given the relevance of these techniques in other research areas and the opportunities to shed new light on existing occupational health problems. In particular, microbiome analyses have the potential to highlight the relationship between occupational exposures and chronic conditions, such as cancers and respiratory diseases, whose etiology has remained elusive. Gene expression studies could elucidate pathways of respiratory irritation among highly exposed workers, with relevance for both the food animal workforce and also the general population. As whole genome sequencing techniques have clarified the role of zoonotic pathogens in the emergence of novel pathogens, such as livestockassociated MRSA and zoonotic influenza viruses, genetic, and genomic techniques hold significant power to clarify pathways of occupational disease for the food animal workforce. This is an important area for future research.

Consideration of pesticide exposures in animal workers, and multiple exposures between crop and animal farmers, also reflects the emerging interest in complex mixtures analyses in occupational exposure assessment. While studies reviewed here did not formally engage mixtures analytic approaches (such as weighted quantile sum regression or lagged kernel machine regression) Davidson and colleagues illustrated the value of combined metrics in exposure assessment studies for food animal workers. Given the complex mixtures of pathogens, allergens, toxicants, and other compounds that food animal workers are exposed to on the job, the application of mixtures methods to occupational health studies of food animal workers is an important next step for the field. These techniques may hold specific relevance for cancer endpoints of relevance to this workforce, whose etiologies are potentially multifactorial and have remained rather elusive to date.

The predominance of research on Latino and migrant worker injury and safety reflect changing demographics in the animal industry over the last 50 years. Food animal production in the USA, including both live animal production as well as processing, remains in a period of demographic transition, with the industry increasingly facing a reckoning between the needs and demands of the immigrant and US-born workforce. As segments of the workforce become increasingly immigrant-based, the specific training needs, and injury experiences of these workers become central. Studies on the effectiveness of safety training and intervention that target the specific needs and experiences of this segment of the workforce are critically important to reducing morbidity in this industry. Likewise, future research that highlights the health experiences and needs of US-born food animal workers, who currently experience wage stagnation and significant social stressors in many regions of the USA, should also be at the forefront. The occupational injury implications of the industry's interests in increased line speeds and also automation also remain an important area for future work, so as to inform regulations and protect workers.

Food animal work remains a complex and often dangerous occupation. Research in 2020 and beyond would best suit the needs of this workforce by continuing to highlight pathogens of concern, identify regulatory and intervention opportunities to reduced occupational pathogen exposure, integrate emerging microbiome and genomic technologies to more fully elucidate occupational disease pathways, and evaluate injuryprevention techniques specific to the demands and realities of the industry.

Funding Information Support for this work was provided by $\mathrm{CDC} /$ NIOSH 5K01OH011432 (JHL) and Williams College Center for Environmental Studies (CD). 


\section{Compliance with Ethical Standards}

Human and Animal Rights This article does not contain any studies with human or animal subjects performed by the authors.

Conflict of Interest The authors declare that they have no conflict of interests.

\section{References}

Papers of particular interest, published recently, have been highlighted as:

- Of importance

•- Of major importance

1. Castillo Neyra R, Vegosen L, Davis MF, Price L, Silbergeld EK. Antimicrobial- resistant bacteria: an unrecognized work-related risk in food animal production. Saf Health Work. 2012;3.

2. Mitchell DC, Armitage TL, Schenker MB, Bennett DH, Tancredi DJ, Langer CE, et al. Particulate matter, endotoxin, and worker respiratory health on large Californian dairies. J Occup Environ Med. 2015;57:79-87.

3. Mitloehner FM, Schenker MB. Environmental exposure and health effects from concentrated animal feeding operations. Epidemiol Camb Mass. 2007;18:309-11.

4. Johnson ES, Choi K-M. Lung cancer risk in workers in the meat and poultry industries-a review. Zoonoses Public Health. 2012;59: 303-13.

5. Department of Labor, Bureau of Labor Statistics. Incidence rates of nonfatal occupational injuries and illnesses by industry and case types. 2015 [Internet]. Available from: https://www.bls.gov/iif/ oshwc/osh/os/ostb4732.pdf

6. Graham JP, Leibler JH, Price LB, Otte JM, Pfeiffer DU, Tiensin T, et al. The animal- human interface and infectious disease in industrial food animal production: rethinking biosecurity and biocontainment. Public Health Rep Wash DC 1974. 2008;123:282-99.

7. Gray GC, McCarthy T, Capuano AW, Setterquist SF, Olsen CW, Alavanja MC. Swine workers and swine influenza virus infections. Emerg Infect Dis. 2007a;13:1871-8.

8. Berendonk TU, Manaia CM, Merlin C, Fatta-Kassinos D, Cytryn E, Walsh F, et al. Tackling antibiotic resistance: the environmental framework. Nat Rev Microbiol. 2015;13:310-7.

9. Silbergeld EK. Chickenizing farms and food: how industrial meat production endangers workers, animals, and consumers. Baltimore: JHU Press; 2016.

10. Otte J, Roland-Holst D, Pfeiffer D, Soares-Magalhaes R, Rushton J, Graham J, et al. Industrial livestock production and global health risks. Food Agric Organ U N -Poor Livest Policy Initiat Res Rep. 2007.

11. Leibler JH, Otte J, Roland-Holst D, Pfeiffer DU, Soares Magalhaes $\mathrm{R}$, Rushton $\mathrm{J}$, et al. Industrial food animal production and global health risks: exploring the ecosystems and economics of avian influenza. EcoHealth. 2009;6:58-70.

12. Brooks JP, Adeli A, McLaughlin MR. Microbial ecology, bacterial pathogens, and antibiotic resistant genes in swine manure wastewater as influenced by three swine management systems. Water Res. 2014;57:96-103.

13. Spencer JL, Guan J. Public health implications related to spread of pathogens in manure from livestock and poultry operations. Methods Mol Biol Clifton NJ. 2004;268:503-15.
14. Smith DL, Harris AD, Johnson JA, Silbergeld EK, Morris JG Jr. Animal antibiotic use has an early but important impact on the emergence of antibiotic resistance in human commensal bacteria. Proc Natl Acad Sci U S A. 2002;99:6434-9.

15. Harper AL, Ferguson DD, Leedom Larson KR, Hanson BM, Male MJ, Donham KJ, et al. An overview of livestock-associated MRSA in agriculture. J Agromedicine. 2010;15:101-4.

16. Koch BJ, Hungate BA, Price LB. Food-animal production and the spread of antibiotic resistance: the role of ecology. Front Ecol Environ. 2017.

17. Price LB, Stegger M, Hasman H, Aziz M, Larsen J, Andersen PS, et al. Staphylococcus aureus CC398: host adaptation and emergence of methicillin resistance in livestock. mBio [Internet]. 2012 [cited 2012 Aug 7];3. Available from: http://www.ncbi.nlm.nih. gov/pubmed/22354957

18. Peiris JSM, de Jong MD, Guan Y. Avian influenza virus (H5N1): a threat to human health. Clin Microbiol Rev. 2007;20:243+.

19. Hogerwerf L, Wallace RG, Ottaviani D, Slingenbergh J, Prosser D, Bergmann L, et al. Persistence of highly pathogenic avian influenza H5N1 virus defined by agro- ecological niche. EcoHealth. 2010;7: 213-25.

20. Brockwell-Staats C, Webster RG, Webby RJ. Diversity of influenza viruses in swine and the emergence of a novel human pandemic influenza A (H1N1). Influenza Other Respir Viruses. 2009;3:20713.

21. Gray GC, Trampel DW, Roth JA. Pandemic influenza planning: shouldn't swine and poultry workers be included? Vaccine. 2007b;25:4376-81.

22. Smith TC, Male MJ, Harper AL, Kroeger JS, Tinkler GP, Moritz ED, et al. Methicillin- resistant Staphylococcus aureus (MRSA) strain ST398 is present in midwestern U.S. swine and swine workers. PloS One. 2009;4:e4258.

23. Castillo Neyra R, Frisancho JA, Rinsky JL, Resnick C, Carroll KC, Rule AM, et al. Multidrug-resistant and methicillin-resistant Staphylococcus aureus (MRSA) in hog slaughter and processing plant workers and their community in North Carolina (USA). Environ Health Perspect. 2014;122.

24. Blood, Sweat and Fear: Workers' Rights in US Meat and Poultry Plants.

25. Grzywacz JG, Alterman T, Muntaner C, Gabbard S, Nakamoto J, Carroll DJ. Measuring job characteristics and mental health among Latino farmworkers: results from cognitive testing. J Immigr Minor Health. 2009;11:131-8.

26. Hiott AE, Grzywacz JG, Davis SW, Quandt SA, Arcury TA. Migrant farmworker stress: mental health implications. J Rural Health Off J Am Rural Health Assoc Natl Rural Health Care Assoc. 2008:24:32-9.

27. Reynolds SJ, Nonnenmann MW, Basinas I, Davidson M, Elfman L, Gordon J, et al. Systematic review of respiratory health among dairy workers. J Agromedicine. 2013;18:219-43.

28. Ramos AK, Carlo G, Grant K, Trinidad N, Correa A. Stress, depression, and occupational injury among migrant farmworkers in Nebraska. Saf Basel Switz. 2016;2:23.

29. Mazurek JM, Henneberger PK. Lifetime allergic rhinitis prevalence among US primary farm operators: findings from the 2011 Farm and Ranch Safety survey. Int Arch Occup Environ Health. 2017;90: 507-15.

30. Bradman A, Whitaker D, Quiros L, Castorina R, Claus Henn B, Nishioka M, et al. Pesticides and their metabolites in the homes and urine of farmworker children living in the Salinas Valley. CA. J Expo Sci Environ Epidemiol. 2007;17:331-49.

31. Sanborn M, Kerr KJ, Sanin LH, Cole DC, Bassil KL, Vakil C. Noncancer health effects of pesticides: systematic review and implications for family doctors. Can Fam Physician Med Fam Can. 2007;53:1712-20. 
32. Tanner CM, Kamel F, Ross GW, Hoppin JA, Goldman SM, Korell $\mathrm{M}$, et al. Rotenone, paraquat, and Parkinson's disease. Environ Health Perspect. 2011;119:866-72.

33. Kamel F, Goldman SM, Umbach DM, Chen H, Richardson G, Barber MR, et al. Dietary fat intake, pesticide use, and Parkinson's disease. Parkinsonism Relat Disord. 2014;20:82-7.

34. Gustafsson B. The health and safety of workers in a confined animal system. Livest Prod Sci. 1997;49:191-202.

35. Linaker C, Smedley J. Respiratory illness in agricultural workers. Occup Med. 2002;52:451-9.

36. Odetokun IA, Ballhausen B, Adetunji VO, Ghali-Mohammed I, Adelowo MT, Adetunji SA, et al. Staphylococcus aureus in two municipal abattoirs in Nigeria: risk perception, spread and public health implications. Vet Microbiol. 2018;216:52-9.

37. Amoako DG, Somboro AM, Abia ALK, Allam M, Ismail A, Bester L, et al. Genomic analysis of methicillin-resistant Staphylococcus aureus isolated from poultry and occupational farm workers in Umgungundlovu District. South Africa. Sci Total Environ. 2019;670:704-16.

38. Chen C-J, Lauderdale T-LY LC-T, Chuang Y-Y, Yang C-C, Wu T-S, et al. Clinical and molecular features of MDR livestockassociated MRSA ST9 with staphylococcal cassette chromosome mecXII in humans. J Antimicrob Chemother. 2018;73: $33-40$.

39. Founou LL, Founou RC, Allam M, Ismail A, Finyom Djoko C, Essack SY. Genome analysis of methicillin-resistant Staphylococcus aureus isolated from pigs: detection of the clonal lineage ST398 in Cameroon and South Africa. Zoonoses Public Health. 2019.

40. Parisi A, Caruso M, Normanno G, Latorre L, Miccolupo A, Fraccalvieri R, et al. MRSA in swine, farmers and abattoir workers in Southern Italy. Food Microbiol. 2019;82:287-93.

41. Sahibzada S, Hernandez-Jover M, Jordan D, Thomson PC, Heller J. Emergence of highly prevalent CA-MRSA ST93 as an occupational risk in people working on a pig farm in Australia. PloS One. 2018;13:e0195510.

42. Stewart-Johnson A, Dziva F, Abdela W, Rahaman S, Adesiyun A. Prevalence of methicillin-resistant Staphylococcus aureus (MRSA) in broilers and workers at "pluck shops" in Trinidad. Trop Anim Health Prod. 2019;51:369-72.

43. Dang STT, Bortolaia V, Tran NT, Le HQ, Dalsgaard A. Cephalosporin-resistant Escherichia coli isolated from farm workers and pigs in northern Vietnam. Trop Med Int Health TM IH. 2018;23:415-24.

44. Borkenhagen LK, Mallinson KA, Tsao RW, Ha S-J, Lim W-H, Toh $\mathrm{T}-\mathrm{H}$, et al. Surveillance for respiratory and diarrheal pathogens at the human-pig interface in Sarawak. Malaysia. PloS One. 2018;13: e0201295.

45.• Ma M-J, Wang G-L, Anderson BD, Bi Z-Q, Lu B, Wang X-J, et al. Evidence for cross-species influenza A virus transmission within swine farms, China: A One Health, Prospective Cohort Study. Clin Infect Dis Off Publ Infect Dis Soc Am. 2018;66: 533-40 The authors identified cross-species transmission of human-adapted H1N1 viruses and swine-adapted H3N2 viruses in both swine and swine workers in China, highlighting continued pandemic influenza risk from swine production in this region. The authors also noted symptomatic influenza-like illness among workers using a longitudinal design, indicating that these zoonotic viruses are pathogenic to humans.

46. Abdelbaset AE, Abushahba MFN, Hamed MI, Rawy MS. Sero-diagnosis of brucellosis in sheep and humans in Assiut and El-Minya governorates. Egypt. Int J Vet Sci Med. 2018;6: S63-7.

47. Brookes VJ, Gill GS, Singh BB, Sandhu BS, Dhand NK, Aulakh $\mathrm{RS}$, et al. Challenges to human rabies elimination highlighted following a rabies outbreak in bovines and a human in Punjab. India. Zoonoses Public Health. 2019;66:325-36.

48. Geng Y, Zhao C, Geng K, Wang C, Wang X, Liu H, et al. High seroprevalence of hepatitis $\mathrm{E}$ virus in rabbit slaughterhouse workers. Transbound Emerg Dis. 2019;66:1085-9.

49. Khounvisith V, Tritz S, Khenkha L, Phoutana V, Keosengthong A, Pommasichan S, et al. High circulation of hepatitis $\mathrm{E}$ virus in pigs and professionals exposed to pigs in Laos. Zoonoses Public Health. 2018;65:1020-6.

50. Msimang V, Thompson PN, Jansen van Vuren P, Tempia S, Cordel C, Kgaladi J, et al. Rift Valley fever virus exposure amongst farmers, farm workers, and veterinary professionals in Central South Africa. Viruses. 2019:11.

51. Cuny C, Layer F, Kock R, Werner G, Witte W. Methicillin susceptible Staphylococcus aureus (MSSA) of clonal complex CC398, t571 from infections in humans are still rare in Germany. PloS One. 2013;8:e83165.

52. Zhou X, Wang Y, Liu H, Guo F, Doi SA, Smith C, et al. Effectiveness of market- level biosecurity at reducing exposure of poultry and humans to avian influenza: a systematic review and meta-Analysis. J Infect Dis. 2018;218:1861-75.

53. Bailey ES, Choi JY, Fieldhouse JK, Borkenhagen LK, Zemke J, Zhang D, et al. The continual threat of influenza virus infections at the human-animal interface: what is new from a one health perspective? Evol Med Public Health. 2018;2018:192-8.

54. Davidson ME, Schaeffer J, Clark ML, Magzamen S, Brooks EJ, Keefe TJ, et al. Personal exposure of dairy workers to dust, endotoxin, muramic acid, ergosterol, and ammonia on large-scale dairies in the high plains Western United States. J Occup Environ Hyg. 2018;15:182-93 The authors conducted personal exposure monitoring for multiple airborne irritants and toxins among dairy workers in the Western US, and considered exposureby-exposure mixtures, setting the stage for future work on complex exposure mixtures in this industry.

55.• Lee MK, Carnes MU, Butz N, Azcarate-Peril MA, Richards M, Umbach DM, et al. Exposures related to house dust microbiota in a U.S. farming population. Environ Health Perspect. 2018;126: 067001-13 The authors evaluated microbial composition of household dust using 16s technology and compared findings to endotoxin levels. This study marks an early foray into microbiome research for understanding health effects associated with occupational exposure to animals.

56. Viegas C, Monteiro A, Ribeiro E, Caetano LA, Carolino E, Assuncao R, et al. Organic dust exposure in veterinary clinics: a case study of a small-animal practice in Portugal. Arh Hig Rada Toksikol. 2018;69:309-16.

57. Chmielowiec-Korzeniowska A, Tymczyna L, Pyrz M, Trawinska B, Abramczyk K, Dobrowolska M. Occupational exposure level of pig facility workers to chemical and biological pollutants. Ann Agric Environ Med AAEM. 2018;25:262-7.

58. El-Zaemey S, Carey RN, Darcey E, Reid A, Glass DC, Benke GP, et al. Prevalence of occupational exposure to asthmagens derived from animals, fish and/or shellfish among Australian workers. Occup Environ Med. 2018;75:310-6.

59. Jeebhay MF, Moscato G, Bang BE, Folletti I, LipinskaOjrzanowska A, Lopata AL, et al. Food processing and occupational respiratory allergy-A EAACI Position Paper. Allergy. 2019.

60. Pouchieu C, Piel C, Carles C, Gruber A, Helmer C, Tual S, et al. Pesticide use in agriculture and Parkinson's disease in the AGRICAN cohort study. Int J Epidemiol. 2018;47:299-310.

61. Darcey E, Carey RN, Reid A, Driscoll T, Glass DC, Benke GP, et al. Prevalence of exposure to occupational carcinogens among farmers. Rural Remote Health. 2018;18:4348.

62. Hofmann JN, Shiels MS, Friesen MC, Kemp TJ, Chaturvedi AK, Lynch CF, et al. Industrial hog farming is associated with altered 
circulating immunological markers. Occup Environ Med. 2018;75: 212-7.

63. Ramos AK, Fuentes A, Carvajal-Suarez M. Self-reported occupational injuries and perceived occupational health problems among Latino immigrant swine confinement workers in Missouri. J Environ Public Health. 2018;2018:8710901.

64. Clouser JM, Bush A, Gan W, Swanberg J. Associations of work stress, supervisor unfairness, and supervisor inability to speak Spanish with occupational injury among Latino farmworkers. J Immigr Minor Health. 2018;20:894-901.

65. Bush AM, Westneat S, Browning SR, Swanberg J. Missed work due to occupational illness among Hispanic horse workers. J Agric Saf Health. 2018;24:89-107.

66. Liebman A, Franko E, Reyes I, Keifer M, Sorensen J. An overview and impact assessment of OSHA large dairy local emphasis programs in New York and Wisconsin. Am J Ind Med. 2018;61:65866. https://doi.org/10.1002/ajim.22868.
67. Rodriguez A, Hagevoort GR, Leal D, Pompeii L, Douphrate DI. Using mobile technology to increase safety awareness among dairy workers in the United States. J Agromedicine. 2018;23:315-26.

68. Caffaro F, Micheletti Cremasco M, Bagagiolo G, Vigoroso L, Cavallo E. Effectiveness of occupational safety and health training for migrant farmworkers: a scoping review. Public Health. 2018;160:10-7.

69. Cuny C, Layer F, Hansen S, Werner G, Witte W. Nasal colonization of humans with occupational exposure to raw meat and to raw meat products with methicillin-susceptible and methicillin-resistant Staphylococcus aureus. Toxins (Basel). 2019; 11:190.

Publisher's Note Springer Nature remains neutral with regard to jurisdictional claims in published maps and institutional affiliations. 